\title{
Immune Enhancer of Bee Propolis
}

\author{
Ahmed Gaffer Hegazi $^{\text {1* }}$, Fayez Mohammed Al Guthami ${ }^{2}$ Ahmed Faiz Al Gethami \\ ${ }^{1}$ National Research Centre, Dokki, Giza, Egypt, and ${ }^{2}$ Al Guthami Foundation, Saudi Arabia \\ *Corresponding author
}

\begin{tabular}{|l|}
\hline Ke y w or d s \\
Immune enhancer, \\
Bee propolis
\end{tabular}

A B S T R A C T

Propolis had been well documented in traditional medicine for treating systemic immune diseases, allergic diseases, viral diseases and organ-specific inflammatory diseases since more than one thousand years. During the last ten years, immunoregulatory and antiinflammatory properties of propolis have been published. The therapeutic characteristics of propolis have been well known for a very long time. It has been used in folk medicine for different nations as early in Egypt as 3000 BC. In recent years, propolis has become a subject of increasing interest for chemists and biologists. It had various biological and therapeutic activities. In in vitro and in vivo assays provided new information concerning its mechanisms of action. Propolis possesses variable biological activities activity was investigated on antiviral, antibacterial, fungicidal, anti-inflammatory, antitumor, antiparasitic, antioxidant, cytokines and immune response. Immunomodulatory and antitumor properties, considering propolis effects on antibody production and on different cells of the immune system which involving the innate and adaptive immune response. This review was aimed to through more light on the enhancing activity of propolis on immune response, and opens a new perspective on the investigation of propolis biological properties on immune mechanism.

\section{Introduction}

Propolis, the resinous product collected by honey bees from plants. Propolis was used specially in antiquity in Egypt. Propolis was very well known to the priests who had monopolized medicine, chemistry and art of mummifying corpses from some thousand years BC (Hegazi, 1998). It is also, demonstrated by the very Greek name as known to the old Greeks. The word propolis is derived from the Greek pro (before) and polis (city). The first head the opinion that bees harvest propolis from resin of willow buds, of poplar, wild chestnut and other plants and other writer assumed that bees harvest it from Styrax (Makashvili, 1978). Propolis. When burnt, it exhibits a smell of aromatic resins of great value. Propolis is used to make the protective shield at the entrance to a hive. Bees use their glue to fill the cracks in the hive, to attach the corners of frames to the grooves in the hive, and also to polish the cells of the honey comb. The bodies of dead lizards, snakes and mice that have entered hives are sealed into the walls with bee glue, thereby 
protecting the colonies against the unpleasant odder and bacterial flora of the putrefying corpses (Ghisalberti et al., 1978).

The Holy Qur'an has a long Sorat (chapter) with the name of bees (Al Nahl). The Ayahs number 68-69 In the name of God Most Gracious, Most Merciful (68) "And thy Lord taught the Bee to build cells in hills, On trees and in (men's) habitations; (69) Then to eat of all The produce (of the earth), And find with skill the spacious Paths of its Lord: there issues From within their bodies A drink of varying colors, Wherein is healing for men: Verily in this is Sign For those who give thought".

Abu Ali bin Sina (Avicenna) distinguishes two kind of wax in his will know work The Canon Medical Science the clean and the black wax. The clean wax is that which composes the comb wells where the bees rear the brood and store the honey and the black was is the filth the hive. It is clear enough that the black wax is propolis that after Avicenna's testimony has the characteristic of eliminating the spikes. It also rarefies, cleans and Soaks. He also writes that by its strong smell, the black wax makes you sneeze.

Propolis is used as folk medicine since ancient time. During the last ten years, immunoregulatory and anti-inflammatory properties of propolis have been published. Propolis ointment used in Folk Georgian medicine, to cure some diseases. There was the custom of placing a propolis cake on the belly button of the newborn baby and also, they rubbed children's toys with propolis. Also, in folk medicine, the use of propolis is widely known especially for the treatment of corns. Also, people inhale propolis in case of affections of respiratory tracts and of the lungs. It is also efficient for burns and angina. The therapeutic characteristics of the propolis have been well known for a very long time.
This is explained by its very pronounced antimicrobial characteristics. Propolis was used effectively on wounds by doctors during the Anglo- Boer war and during The World War II. It was also used in hospitals. From 1969 Orthodox medicine in USSR accepted the use of propolis $30 \%$ (30\% alcoholic solution of propolis). It is produced by the pharmaceutical product plant in Tallinn (Makashvili, 1978).

Beekeepers well-known propolis, or "bee glue," that find in their hives. It is a resinous product collected by honeybees. It is being dark green or brown in color with a pleasant flavor of poplar buds, honey, wax and vanilla but it can also have a bitter taste. It is used by bees as glue in general-purpose as well as is used in folk medicine for long time in different nations (Hegazi and Abd El Hady, 2008).

The knowledge since humans have used propolis for different purposes, its properties with scientific basis is not only of academic interest but also of those who use propolis as well (Sforcin, 2007). The primary function of the innate immune system is the detection of pathogens (Banskota et al., 2001) and the rapid activation of host defense mechanisms (Iwasaki and Medzhitov, 2004 and Yarovinsky and Sher, 2006). The detailed mechanisms of actions of propolis and its components on immune cells, however, are still unknown. Cytokines (Greek cyto-, cell; and -kinos, movement) are a category of signaling molecules that are used extensively in cellular communication (Weaver et al., 2007). They are proteins, peptides, or glycoproteins. The term cytokine encompasses a large and diverse family of polypeptide regulators that are produced widely throughout the body by cells of diverse embryological origin. (Gilman et al., 2001). Cytokines are small secreted proteins which mediate and regulate immunity, inflammation and hematopoiesis. Cytokine is a general 
name; other names include lymphokine (cytokines made by lymphocytes), monokine (cytokines made by monocytes), chemokine (cytokines with chemotactic activities), and interleukin (cytokines made by one leukocyte and acting on other leukocytes).

Cytokines are a category of signaling molecules used extensively in cellular communication. Cytokines are produced by a broad range of cells, including immune cells like macrophages, $\mathrm{B}$ lymphocytes, $\mathrm{T}$ lymphocytes and mast cells, as well as endothelial cells, fibroblasts, and various stromal cells; a given cytokine may be produced by more than one type of cells (). They released by cells and affect the behavior of other cells, and sometimes the releasing cell itself (Watford et al., 2003). Cytokines acts through receptors, and are especially important in the immune system; cytokines modulate the balance between humoral and cell-based immune responses, and they regulate the maturation, growth, and responsiveness of particular cell populations.

The propolis contains a variety of biologically active compounds such as flavonoids, vitamins, antioxidants and hydrogen peroxides (Hegazi and Abd El Hady, 2002 and Abd ElHady et al., 2007). Due to its biological properties as antiprotozoal (Hegazi et al., 2014b and Hegazi et al., 2018), antiparasitic (Hegazi et al., 2007a,b and Gaddi and Yap, (2007), antimicrobial (Hegazi and Abd El Hady, 2001; Park et al., 2004; and Hegazi et al., 2014a), antifungal (Hegazi et al., 2000), and antiviral agent (Hegazi et al., 2012, and Fan et al., 2013), hepatoprotective (Gonzales et al., 1995), antioxidant (Abd El Hady et al., 2007), immunostimulating (Hegazi and Abd El Hady, 1994, and Takagi et al., 2005), localized plaque psoriasis (Hegazi et al., 2013) and cytostatic (Banskota et al., 2001).

The chemical composition of propolis appeared to be extremely complex and more than 300 compounds have been identified so far (Marcucci, 1995), the most important ones being polyphenols (Hegazi and Abd El Hady, 1997). Propolis is a well-known bee product containing more than 2000 identified compounds (Bojić et al., 2018).

The major components of propolis exerted beneficial effects by polyphenols, caffeic acid phenethyl ester (CAPE), chrysin and other flavonoids (Hegazi et al., 2000; Hegazi and Abd El Hady, 2002; Hegazi et al., 2007a, b). Propolis has modulatory action on murine peritoneal macrophages, increasing their microbicidal activity and stimulant action on antibody production (Sforcin, 2007). The synergistic effects of wide range of compounds present in propolis are the results of antioxidants activity (Hegazi and Abd $\mathrm{Al}$ Hady, 2009) and hepatocytes protection (ElKhatib et al., 2002) and anti-inflammatory (Rashid et al., 2016).

Propolis contains natural flavonoid, chrysin (5,7-dihydroxyflavone), it has beneficial effects including anti-tumor and anti-oxidant activities. The mode of action of chrysin is to decrease gene expression of pro-inflammatory cytokines such as, tumor necrosis factor- $\alpha$, IL (interleukin)-1 $\beta$, IL-4, and IL-6 in mast cells (Bae et al., 2011). Chrysin also significantly reduced the serum levels of pro-inflammatory cytokines, interleukin-1 beta (IL-1 $\beta$ ) and IL-6 (Fitzpatrick et al., 2001 and Ahad et al., 2014). Ansorge et al., (2003) demonstrate that propolis has a direct regulatory effect on basic functional properties of immune cells where cytokines produced by monocytes/ macrophages (IL-1 $\beta$, IL-12), by Th1 type (IL2) as well as Th2 type (IL-4) lymphocytes were found to be also suppressed. Also, Mossalayi et al., ((2014) found that propolis decreased both monokines and interferon $\gamma$ $(\mathrm{IFN} \gamma)$ production and induces potent antiinflammatory activity due to their complementary immune cell modulation. Propolis inhibitory effects on 
lymphoproliferation may be associated to its anti-inflammatory property. In immunological assays, the best results were observed when propolis was administered over a short-term to animals (Sforcin, 2007). Inflammatory cytokines and oxidative stress have a central role in the pathogenesis of acute pancreatitis. Propolis has anti-inflammatory and antioxidant effects. The therapeutic role of ethanolic extract of propolis on a ceruleininduced acute pancreatitis model in rats was investigated by üyükberber et al., (2009). They found in the acute pancreatitis group, the tissue revealed massive edema and inflammation with less fatty necrosis when compared to the sham and control groups. In the ethanolic extract of propolis group, in particular, tissue edema was improved markedly ( $\mathrm{p}=0.001)$. Tissue inflammation and fatty necrosis were decreased with ethanolic extract of propolis treatment.

Girgin et al., (2009) studied, the immunomodulatory effects of six Turkish propolis samples were evaluated by using the in vitro model of peripheral blood mononuclear cells (PBMC). The benefit of propolis, in most of the diseases the cellular immune reaction is activated, neopterin levels in body fluids are increased and enhanced tryptophan degradation is observed. Concentrations of neopterin, tryptophan, kynurenine and pro-inflammatory cytokines, tumor necrosis factor-alpha (TNF-alpha) and interferon-gamma (IFN-gamma) were determined. In PBMC treated with mitogen phytohaemagglutinin, neopterin production and tryptophan degradation by enzyme indoleamine 2,3-dioxygenase (IDO) as well as release of cytokines was significantly enhanced and upon treatment with propolis extracts all these effects were dosedependently suppressed. Caffeic acid phenethyl ester (CAPE) is a biologically active component of propolis, a resinous material obtained from bee hives. Song et al.,
(2008) evaluated the anti-inflammatory effect of CAPE on cultured human middle ear epithelial cells (HMEECs). They suggested that the anti-inflammatory effect of caffeic acid phenethyl ester (CAPE) is due to its inhibition of tumor necrosis factor (TNF)alpha expression and interleukin (IL)-8 production. The anti-inflammatory effect of CAPE is possibly through the inhibition of nuclear factor (NF)-kappaB via the suppression of inhibitor-kappaB-alpha (IkappaB-alpha) degradation.

Caffeic acid phenethyl ester (CAPE) is an active component of honeybee propolis extracts. It has several positive effects, including anti-inflammatory, anti-oxidation, anti-cancer, anti-bacterial, anti-viral, antifungal, and immunomodulatory effects. In particular, the suppressive effect of NFkappaB may disrupt a component of allergic induction. Jung et al., (2008) determined whether treatment with CAPE results in significant inhibition of asthmatic reactions in a mouse model. An increase in the number of eosinophils in bronchoalveolar lavage (BAL) fluid; a marked influx of inflammatory cells into the lung around blood vessels and airways, and airway luminal narrowing; the development of airway hyperresponsiveness (AHR); the presence of tumor necrosis factoralpha (TNF-alpha) and Th2 cytokines, including IL-4 and IL- 5, in the BAL fluid; and the presence of allergen-specific $\operatorname{IgE}$ in the serum.

Choi and, Choi (2008) reported that CAPE exerts its anti-inflammatory action (inhibition of tumor necrosis factor-induced expression of intercellular adhesion molecule-1 and CC chemokine ligand-2) via NF-kappaB inhibition by two distinct molecular mechanisms in a cell-specific manner: CAPE inhibited downstream pathways of inhibitor kappaB (IkappaB) degradation in monocytic cells, while activation of upstream IkappaB 
kinase was suppressed by CAPE pre-treatment in astroglial cells; and (ii) CAPE paradoxically activates the c-Jun N-terminal kinase (JNK) pathway, which might be responsible for its pro-apoptotic action and divergent regulation of proinflammatory mediators such as CXC chemokine ligand-8. Park et al., (2004) evaluated the effects of CAPE on the active systemic anaphylaxis induced by ovalbumin (OVA) challenge in mice. Histopathological analysis, nuclear factor (NF)-kappaB activation, and the plasma levels of histamine and total $\operatorname{IgE}$ after allergen challenge were evaluated. After challenges, all of the shamtreated mice developed anaphylactic symptoms, increased plasma levels of histamine and OVA-specific IgE, marked vascular leakage, NF-kappaB activation, platelet-activating factor (PAF) production, and histological changes. Sy et al., (2006) found that the higher dose of propolis extracts decreases the level of IL- 5 in BALF. The splenocytes from mice administered with propolis extracts (low- and high-dose groups) exhibit a strong inhibition of IL-10 secretion and up-regulation of IFN-gamma secretion in splenocytes stimulated with concanavalin A (ConA). In addition, cytokine (IFN-gamma, IL-6, and IL-10) secretion in OVA-stimulated splenocytes from the propolis groups was significantly lower than that in the control group. These results suggest that propolis extracts may be a potential novel therapeutic agent for asthma.

Furthermore, CAPE suppressed $H$. pyloriinduced cell proliferation and production of the cytokine's TNF-alpha and IL- 8. In addition, CAPE blocked $H$. pylori-induced COX-2 expression. The inhibition of such transcription by CAPE could result in suppression of many genes during $H$. pyloriinduced inflammation, and also provide new insights into the anti-cancer and antiinflammatory properties of CAPE (AbdelLatif et al., 2005). Márquez et al., (2004) evaluated the immunosuppressive activity of CAPE in human T-cells, discovering that this phenolic compound is a potent inhibitor of early and late events in T-cell receptormediated $\mathrm{T}$-cell activation. They found that CAPE specifically inhibited both interleukin (IL)-2 gene transcription and IL-2 synthesis in stimulated T-cells. To further characterize the inhibitory mechanisms of CAPE at the transcriptional level. Takagi et al., (2005) focused on immune stimulation by Propolis, and examined changes in the effect of irradiation after Propolis administration. They found that cytokines released from macrophages in mouse peripheral blood after Propolis administration activated helper $\mathrm{T}$ cells to proliferate. In addition, activated macrophages in association with the secondary T-lymphocyte activation increased IFN-gamma production and stimulated proliferation of cytotoxic T-cells and suppressor T-cells, indicating the activation of cell-mediated immune responses. Blonska et al., (2004) indicated that EEP exerts its inhibitory effect on the IL-1beta and iNOS gene expression in J774A.1 macrophage at the transcriptional level.

Tested flavone derivatives contribute to the anti-inflammatory activity of propolis. The cytokine, IL-2, IL-4 and IFN-gamma were significantly increased at the dose of $20 \mathrm{mg} / \mathrm{kg}$ CAPE group. These results suggest that CAPE could have immunomodulatory effects in vivo (Park et al., 2004). Ansorge et al., (2003) studied the effects of different propolis extracts, of the flavonoids hesperidin and quercetin as well as of caffeic acid phenethyl ester (CAPE) on basic human immune cell functions by measuring the effects on DNA synthesis and production of different types of cytokines, namely IL-1beta, IL-12, IL-2, IL-4, IL-10 and TGF-beta1, of mitogen-activated peripheral blood mononuclear cells (PBMC) as well as of purified T lymphocytes. The data clearly 
showed that propolis was capable of dosedependently suppressing phythemagglutinin (PHA)-induced DNA synthesis of PBMC and $\mathrm{T}$ cells. Moreover, cytokines produced by monocytes/macrophages (IL-1beta, IL-12), by Th1 type (IL-2) as well as Th2 type (IL-4) lymphocytes were found to be also suppressed, whereas the production of TGFbeta1 by $\mathrm{T}$ regulatory cells was ascertained to be increased.

The immune system has a variety of regulatory/suppressive processes, which are decisive for the development of a healthy or an allergic immune response to allergens. NK1 and NK2 subsets have been demonstrated to display counter regulatory and provocative roles in immune responses, similar to Th1 and Th2 cells. T regulatory cells suppressing both Th1 and Th2 responses have been the focus of intensive research during the last decade. Deniz et al., (2008) investigated the regulatory $\mathrm{NK}$ cells in humans, by characterization of NK cell subsets according to their IL-10 secretion property. Freshly purified IL-10-secreting NK cells expressed up to 40-fold increase in IL10. The effect of IL-10+ NK cells on Agspecific $\mathrm{T}$ cell proliferation has been examined in bee venom major allergen, phospholipase A2- and purified protein derivative of Mycobecterium bovis-induced T cell proliferation. IL-10+ NK cells significantly suppressed both allergen/Aginduced $\mathrm{T}$ cell proliferation and secretion of IL-13 and IFN-gamma, particularly due to secreted IL-10 as demonstrated by blocking of the IL-10 receptor. These results demonstrate that a distinct small fraction of NK cells display regulatory functions in humans. Immunomodulatory and antitumor properties, considering propolis effects on antibody production and on different cells of the immune system which involving the innate and adaptive immune response. The propolis modulatory action on murine peritoneal macrophages leading to increase their microbicidal activity, this was confirmed by in vitro and in vivo assays. Also, its stimulant antibody production and increase action on the lytic activity of natural killer cells against tumor cells. The inhibitory effects of propolis on lymphoproliferation may be associated to its anti-inflammatory property (Sforcin, 2007).

Yang et al., (2014) found that in vitro propolis flavonoids liposome can significantly enhance the phagocytic function of macrophages and the release of IL-1 $\beta$, IL- 6 , and IFN- $\gamma$ and activate the cellular and humoral immune response, including higherlevel of IgG, IL-4, and IFN- $\gamma$ in serum and the proliferation rates of splenic lymphocytes. Hegazi et al., (2017) studded the influence of Egyptian propolis on immunological responses with special reference to cytokine levels of infected rats with Toxoplasma gundi and treated with $0.1 \mathrm{ml}$ propolis day after day till the end of the experiment (28 days). Immune response of rats was evaluated weekly. They found that the propolis was the highest in the toxoplasma antibodies titer when comparing with control group from the 2nd week to the end of experiment. Serum level of cytokines was consistently higher in the treated and propolis infected rats compared with controls. Serum levels of IFN$\gamma$, IL-1B and IL-6 were decreased in propolis and returned to infection at day 7 postinfection.

\section{References}

Abd El-Hady F. K; Hegazi A. G. and Wollenweber E. (2007): Effect of Egyptian Propolis on the Susceptibility of LDL to Oxidative Modification and its Antiviral Activity with Special Emphasis on Chemical Composition. Z. Naturforsch. 62c, 645- 655.

Abdel-Latif MM, Windle HJ, Homasany BS, 
Sabra K, Kelleher D. (2005) Caffeic acid phenethyl ester modulates Helicobacter pylori-induced nuclear factor-kappa $\mathrm{B}$ and activator protein-1 expression in gastric epithelial cells. $\mathrm{Br}$ J Pharmacol. 146(8):1139-47.

Ahad A, Ganai AA, Mujeeb M, Siddiqui WA.Chrysin, an anti-inflammatory molecule, abrogates renal dysfunction in type 2 diabetic rats. Toxicol Appl Pharmacol. 2014; 279(1):1-7.

Ansorge S, Reinhold D, Lendeckel U. (2003) Propolis and some of its constituents down-regulate DNA synthesis and inflammatory cytokine production but induce TGF-beta1 production of human immune cells. Z Naturforsch C. 58(7-8): 580-9.

Bae Y, Lee S, Kim SH. Chrysin suppresses mast cell-mediated allergic inflammation: involvement of calcium, caspase-1 and nuclear factor- $\kappa \mathrm{B}$. Toxicol Appl Pharmacol. 2011; 254(1):56-64.

Banskota A.H., Y. Tezuka and S. Kadota. 2001. Recent progress in pharmacological research of propolis. Phytoth. Res., 15: 561-571.

Blonska M, Bronikowska J, Pietsz G, Czuba ZP, Scheller S, Krol W. (2004) Effects of ethanol extract of propolis (EEP) and its flavones on inducible gene expression in J774A.1 macrophages. J Ethnopharmacol. 91(1):25-30.

Bojić M., Antolić A., Tomičić M., Debeljak Z. and Maleš Ž. (2018): Propolis ethanolic extracts reduce adenosine diphosphate induced platelet aggregation determined on whole blood. Nutrition Journal (2018) 17:52

Büyükberber M, Savaş MC, Bağci C, Koruk M, Gülşen MT, Tutar E, Bilgiç T, Deveci R, Küçük C. (2009) The beneficial effect of propolis on ceruleininduced experimental acute pancreatitis in rats. Turk J Gastroenterol. 20(2):122-
8.

Choi K and Choi C. (2008) Differential regulation of c-Jun $\mathrm{N}$-terminal kinase and NF-kappaB pathway by caffeic acid phenethyl ester in astroglial and monocytic cells. J Neurochem. 105(2):557-64.

Deniz G, Erten G, Kücüksezer UC, Kocacik D, Karagiannidis C, Aktas E, Akdis CA, Akdis M. (2008) Regulatory NK cells suppress antigen-specific $\mathrm{T}$ cell responses. J Immunol. 15; 180(2):8507.

El-Khatib AS, Agha AM, Mahran LG, Khayyal MT. Prophylactic effect of aqueous propolis extract against acute experimental hepatotoxicity in vivo. Z Naturforsch C. 2002; 57(3-4): 379-85.

Fan Y, Lu Y, Wang D, Liu J, Song X, Zhang W, Zhao X, Nguyen TL, Hu Y. (2013): Effect of epimedium polysaccharidepropolis flavone immunopotentiator on immunosuppression induced by cyclophosphamide in chickens. Cell Immunol. 281(1):37-43.

Fitzpatrick LR, Wang $\mathrm{J}$ and Le T. Caffeic acid phenethyl ester, an inhibitor of nuclear factor-kappaB, attenuates bacterial peptidoglycan polysaccharideinduced colitis in rats. J Pharmacol Exp Ther. 2001; 299(3):915-20.

Gaddi PJ and Yap GS Cytokine regulation of immunopathology in toxoplasmosis. Immunology and Cell Biology (2007) $85,155-159$

Ghisalberti, E.L.; Jefferies, P.R.; Lanteri, R. and Matisons, J. (1978): Constituents of propolis. Experientia, 34(2): 157-158.

Gilman A, Goodman LS, Hardman JG, Limbird LE (2001). Goodman \& Gilman's the pharmacological basis of therapeutics. New York: McGraw-Hill. ISBN 0-07-135469-7.

Girgin G, Baydar T, Ledochowski M, Schennach H, Bolukbasi DN, Sorkun K, Salih B, Sahin G, Fuchs D. (2009) 
Immunomodulatory effects of Turkish propolis: changes in neopterin release and tryptophan degradation. Immunobiology. 214(2):129-34.

Gonzales R., I. Corcho, D. Remirez, S. Rodriguez, O. Ancheta, N. Merino, A. Gonzales and C. Pascual, 1995. Hepatoprotective effects of propolis extract on carbon tetrachloride-induced liver injury in rats. Phytoth. Res., 9: 114-117.

Hegazi A. G. (2009): Propolis in correlation to cytokines - Part II. Apitherapy Review, Issue 4.

Hegazi A.G. and Faten, K. Abd El Hady. (1997): Chemical and biological studies of Egyptian propolis. International Symposium on Apitherapy, Cairo 8-9th, March, 1997.

Hegazi A. G. and F.K Abd El Hady (2008) Egyptian propolis in Scientific Evidence of the Use of Propolis in Ethnomedicine, 79-119, ISBN: 978-817895-357-1 Editors: Nada Oršolić and Ivan Bašić Transworld Research Network 37/661 (2), Fort P.O., Trivandrum-695 023, Kerala, India

Hegazi A. G., Faten K. Abd El Hady and Shalaby H. A. (2007a): An in vitro effect of propolis on adult worms of Fasciola gigantica. Vet. Parasit. 144: 279-286.

Hegazi A. G., Faten K. Abd El Hady and Shalaby H. A. (2007b): Inhibitory Effect of Egyptian Propolis on Fasciola gigantica Eggs with Reference to its Effect on Clostridium oedematiens and Correlation to Chemical Composition Pakistan Journal of Biological Sciences 10 (19): 3295-3305. Hegazi, A. G. (1998): Propolis an over view. J. Bee Informed 5:5, 22 -23, 6:723-28.

Abd El Hady F. K. and A. G.Hegazi (1994): Gas chromatography mass spectrometry (GC/MS) study of the Egyptian propolis. 1- Aliphatic acids and their esters. Egypt. J. Appl. Sci., 9 (7): 749-760.

Hegazi, A. G. and F. K. Abd El Hady. (2002): Egyptian propolis: 3 Antioxidant, antimicrobial activity and chemical composition of propolis from reclaimed land. Z. Naturforsch $57 \mathrm{c}$, 395-402.

Hegazi, A. G., Abd El Hady F K. and Abd Allah F. M. (2000) Chemical composition and antimicrobial activity of European propolis. Z. Naturforsch. 55c, 71-75.

Hegazi A.G., Abdou A. M. and Fyrouz Abd Allah (2012): Egyptian Propolis 9- It's effect on chicken productivity and immune response against Newcastle Disease Vaccine. British Journal of Poultry Sciences 1(3): 25-30.

Hegazi A.G. Fatma A. Abd Raboh; Nahla Ramzy, Dalia Shaban and Doha Y. Khader (2013): Bee venom and propolis as new treatment modality in patients with localized plaque psoriasis. International J. Med. Med. Sci. 1(2), 2733.

Hegazi A.G., Abdou A. M. and Abd Allah F. (2014a): Egyptian Propolis 1I: Antimicrobial activity with comparison with deferent different localities. Int. J. Curr.Microbiol. App. Sci 3(9) 530-538.

Hegazi A.G., El-Fadaly H. A., Barakat A. M.and Abou-El-Doubal Sanaa K.A. (2014b): In vitro Effects of Some Bee Products on $\mathrm{T}$. gondii Tachyzoites. Global Veterinaria 13 (6): 1043-1050.

Hegazi A. G. Al Guthami, F. M, Al Gethami AF. M. and Barakat A M. (2017): Egyptian Propolis 12: Influence of Propolis on Cytokines of Toxoplasma gondii Infected Rats. Int.J.Curr.Microbiol.App.Sci. 6 (5): 202-211

Hegazi, A. G. and F. K. Abd El Hady. (2001): Egyptian propolis: 1Antimicrobial activity and chemical 
composition of Upper Egypt propolis. Z. Naturforsch 56c, 82-88.

Hegazi AG, Abdel Megeed KN, Hassan SE, Abdelaziz MM, Toaleb NI, El Shanawany EE, and Aboelsoued D (2018): Comparative ovicidal activity of Moringa oleifera leaf extracts on Fasciola gigantica eggs, Veterinary World, 11(2): 215-220.

Ibelgaufts $\mathrm{H}$. Cytokines in Cytokines and Cells Online Pathfinder Encyclopedia Version 31.4 (Spring/Summer 2013 Edition).

Iwasaki, A., Medzhitov, R., 2004. Toll-like receptor control of the adaptive immune responses. Nat. Immunol. 5, 987-995.

Jung WK, Lee DY, Choi YH, Yea SS, Choi I, Park SG, Seo SK, Lee SW, Lee CM, Kim SK, Jeon YJ, Choi IW. (2008) Caffeic acid phenethyl ester attenuates allergic airway inflammation and hyperresponsiveness in murine model of ovalbumin-induced asthma. Life Sci. 26; 82(13-14):797-805.

Lackie J. "Cytokine" in. A Dictionary of Biomedicine. Oxford University Press.. ISBN 9780199549351; 2010.

Makashvili,Z. A.(1978) From the history of propolis. In Remarkable hive product: Propolis. Scientific data and suggestions concerning its composition, properties and possible use in therapeutics. APIMONDIA standing Commission on Beekeeping technology and Equipment, Bucharest.

Marcucci M. C. (1995), Propolis: Chemical composition, biological properties and therapeutic activity. Apidologie 26, 8399.

Márquez N, Sancho R, Macho A, Calzado MA, Fiebich BL, Muñoz E. (2004) Caffeic acid phenethyl ester inhibits Tcell activation by targeting both nuclear factor of activated T-cells and NFkappaB transcription factors. $\mathbf{J}$ Pharmacol Exp Ther. 308(3): 993-1001.
Mossalayi MD, Rambert J, Renouf E, Micouleau M2, Mérillon JM.Grape polyphenols and propolis mixture inhibits inflammatory mediator release from human leukocytes and reduces clinical scores in experimental arthritis. Phytomedicine. 2014; 21(3):290-7.

Park JH, Lee JK, Kim HS, Chung ST, Eom JH, Kim KA, Chung SJ, Paik SY, Oh HY. (2004) Immunomodulatory effect of caffeic acid phenethyl ester in Balb/c mice. Int Immunopharmacol. 4(3): 42936.

Rashid S, Nafees S, Vafa A, Afzal SM, Ali N, Rehman MU, Hasan SK, Siddiqi A, Barnwal P, Majed F, Sultana S. Inhibition of precancerous lesions development in kidneys by chrysin via regulating hyperproliferation, inflammation and apoptosis at pre clinical stage. Arch Biochem Biophys. 2016;606:1-9. doi: 10.1016/j.abb.2016. 07.004. Epub 2016 Jul 9.

Sforcin, J.M. Propolis and the immune system: a review. Journal of Ethnopharmacology. 2007, 113,(1),114

Song JJ, Cho JG, Hwang SJ, Cho CG, Park SW, Chae SW. (2008) Inhibitory effect of caffeic acid phenethyl ester (CAPE) on LPS-induced inflammation of human middle ear epithelial cells. Acta Otolaryngol. 2008; 128(12):1303-7.

Sy LB, Wu YL, Chiang BL, Wang YH, Wu WM. (2006) Propolis extracts exhibit an immunoregulatory activity in an OVAsensitized airway inflammatory animal model. Int Immunopharmacol. 6(7):1053-60.

Takagi Y., I.S. Choi, T. Yamashita, T. Nakamura, I. Suzuki, T. Hasegawa, M. Oshima and Y.H. Gu. 2005. Immune activation and radioprotection by propolis. Am. J. Chin. Med. 33(2): 23140.

Watford W T, Moriguchi M, Akio Morinobu 
A and O'Shea J J. The biology of IL12: coordinating innate and adaptive immune responses. Cytokine. 2003; 14: (5), 361-368.

Weaver CT, Hatton R D, Mangan PR and Harrington L E. IL-17 Family cytokines and the expanding diversity of effector $\mathrm{T}$ cell Lineages. Annual Review of Immunology. 2007; 25: 821-852.

Yang Tao, Deqing Wang, Yuanliang $\mathrm{Hu}$, Yee Huang, Yun $\mathrm{Yu}$, and Deyun Wang (2014): The Immunological
Enhancement Activity of Propolis Flavonoids Liposome in vitro and in vivo. Evidence-Based Complementary and Alternative Medicine 2014, Article ID 483513,8 pages

Yarovinsky F, Sher A. Toll-like receptor recognition of Toxoplasma gondii International Journal for Parasitology 36 (2006) 255-259

\section{How to cite this article:}

Ahmed Gaffer Hegazi, Fayez Mohammed Al Guthami, Ahmed Faiz Al Gethami. 2018. Immune Enhancer of Bee Propolis. Int.J.Curr.Microbiol.App.Sci. 7(11): 2583-2592.

doi: https://doi.org/10.20546/ijcmas.2018.711.294 